\title{
Clinical Stage IIB Esophageal Adenocarcinoma AJCC v8
}

National Cancer Institute

\section{Source}

National Cancer Institute. Clinical Stage IIB Esophageal Adenocarcinoma A/CC v8. NCI

Thesaurus. Code C133406.

Stage IIB includes: T2, N0, M0. T2: Tumor invades the muscularis propria. N0: No regional lymph node metastasis. M0: No distant metastasis. (AJCC 8th ed.) 